Lytra. V., Ros i Solé, C., Anderson, J., and V. Macleroy. Forthcoming 2022. 'Conclusion: Language Education Collages'. In: Lytra. V., Ros i Solé, C., Anderson, J., and V. Macleroy (eds) Liberating Language Education. Bristol: Multilingual Matters, 321-330.

\title{
Conclusion: Language Education Collages
}

\section{Vally Lytra, Cristina Ros i Solé, Jim Anderson and Vicky Macleroy}

This book has brought home the idea that language education is about listening. Listening to what happens on the ground: the work of language teachers, educators and literacy specialists, and the connections that are made in between. It aligns with ways of doing that move away from ideal, disembodied and abstract processes that are applied top-down. In doing this, it has shown that language education finds its temporary shapes and contours by identifying with particular localities, inhabiting particular practices, and connecting with the different voices and relationships taking part in it.

Language education in this book listens to the needs and wishes of each actor and voices in this self-organising ensemble of meaning-making. All dependent on each other in a interdependent ecosystem. It argues that language education works best and more creatively when questioning hierarchies and linear paths whilst at the same time acknowledging the pull of ideology and its constraining structures. Indeed, the political and critical aspect of the empowering role of language education to combat and fight hegemony, power and inequality is not something that this volume shies away from. It recognises that not all languages and all speakers are on a level-playing field, as the recent pandemic has made apparent.

As we write the conclusion for this book in the midst of the pandemic, it has become evident that we don't have as much control over our environment as rational epistemologies in western thought assume. How we relate to the world and the way our agencies work is relational and contingent on how the world changes around us. The pandemic has reminded us that we need to be open to new possibilities, unforeseen circumstances and be adaptable to change as one thing leads to another in a complex web of connections and relationships. Similarly, the individual personal aspects of language education, with their biographical and historical aspects are unpredictable and contingent on a myriad of events. But above all, they are in tension with the political. It is only by acknowledging the power of social structures that the personal is able to unfold and function. So that it is through the inter and intrarelationships between the two that there is the possibility for change and creativity, and of finding new ways of doing language education. Whilst there is more than one direction to go, there is also more than one voice to be taken into account. Each context, history and confederation of circumstances and agencies are made up of different collages of literacies and language learning.

But we also listen to silence. We listen and acknowledge the richness that other semiotic processes bring to language within an expanded view of meaning-making. We listen to the silent manifestations of language: the aesthetic and the sensory. As the different sections and chapters in this book have shown, language can be conceived in a variety of ways and in combination with the other noise, the cacophony of multisensory and multimodal expressive modes: whether it is through the visual arts, crafts, textures or smells.

This vision of language education is therefore one that emerges out of both verbal and nonverbal, purposeful and intuitive relationships and connections. These are junctures that often clash, grapple and subvert unequal power relations whilst at the same time engender creative 
processes and unexpected becomings. Whereas a harmonious language ensemble and coherent linguistic repertoire is often the end goal, we recognise that there is crisis and catharsis, pain and pleasure along the way, and the lingering feeling that external forces and constraints prevail. There will be compromises, and dialogue with other agencies, some limitations and influences. This, however, does not mean that it has not worked, but rather that the task of liberating language education is never finished and is always at work, open, full of possibility and in movement. Indeed, liberating language education is not a free-forall, an unmoored pedagogy with no anchors. It just means that fixtures are temporary, contingent on the local circumstances in which it finds itself, and always susceptible to change.

We also hope to make a call for liberating language education from a particular way of researching language education. One that is not subject to the hegemony of theory and exclusively rational approaches to language. Instead, we propose different ways of working with theory that emphasize dialogue and collaborative approaches. A way of working with theory that listens to both researchers and participants and the meanings that emerge as a result of such collaborative work.

This liberatory language education vision is one that hopes to be enabling rather than constraining. One that not only encourages us to listen to and hear new voices but that also hopes to create new ones. It is theory-in-progress, unfinished and open to new possibilities, new landscapes and new forms of knowledge. It listens to and observes every classroom, every context and circumstance, and in doing so, it focuses on the nexus of time and space and the textures, colours and shapes that give it form.

The vision of language education exposed in this book is not an example of language education that is conjured up and imagined in our minds out of some grand plan. Rather, it seeks to trace the particular, an infinite collage of scraps of real-life events, formal and informal, histories and biographies that form constellations of agencies, practices and eduscapes whilst providing the starting point for new creative formations. This is no theory of language education to be transferred and applied to any context, but rather, a way of educating our sensibility to pick up the frequencies and directions that language education can branch out into.

\section{Where do we go next?}

[...] When the children return to school, they will have returned with a new history that we will need to help them identify and make sense of. When the children return to school, we will need to listen to them. Let their stories be told. [...] Greet them with art supplies and writing materials, and music and dance and so many other avenues to help them express what has happened to them in their lives during this horrific year. Greet them with stories and books that will help them make sense of an upside-down world. [...] Resist the pressure from whatever 'powers that be' who are in a hurry to "fix" kids and make up for the "lost" time. The time was not lost, it was invested in surviving an historic period of time in their lives - in our lives. The children do not need to be fixed. They are not broken. They need to be heard. [...] (Thayer Snyder, 2020)

As we draft the conclusion to Liberating Language Education the pandemic has disrupted and changed (language) learning for millions of learners and their families, and for language educators around the globe. The extract above is from a Facebook post by Teresa Thayer 
Snyder (former superintendent of the Voorheesville district in upstate New York). The post urges us to rethink and reimagine the purposes, practices, and processes of (language) education using as our compass the experiences, narratives and socio-emotional needs of the learners themselves. Dominant monolingual discourses and exclusionary cultural practices can ignore, alienate, and silence learners' voices, their rich histories, heritages, languages, ways of knowing and being that do not fit neatly in established educational models and benchmarks. Rather than succumbing to deficit representations and understandings of children as "need[ed] to be fixed" Teresa Thayer Snyder advocates an alternative narrative that children "need to be heard". She stresses that learning stretches well beyond the narrowly defined academic curriculum, achievement measurements and the physical boundaries of schools and classrooms. Children bring to academic knowledge valuable "funds of knowledge" (González et al., 2005) they have acquired and developed in their homes and communities, as they participate in often intergenerational social networks with a range of significant mediators, e.g., parents, grandparents, siblings, peers, pets. Teresa Thayer Snyder emphasises the emancipatory potential of the arts, storytelling, and books in unlocking children's worlds and experiences. This potential builds on learners' existing funds of knowledge but also creates new possibilities, new funds of knowledge "for creating new futures through the work of critically understanding and re-imagining their cultural-historical present" (Zipin et al., 2011: 188). Teresa Thayer Snyder's words amid the second lockdown, school closures and home schooling across many countries worldwide ring with a sense of urgency that powerfully speak to insights offered in this book.

The chapter authors bring to the fore, individually and collectively, new possibilities and reimaginings of how languages and cultures can be lived and how language learning environments that capitalise on learners' extant and new funds of knowledge can be nourished. In doing so, they create "openings" (Alison Phipps, commentary); they strive for "a new way of listening" (Kate Pahl, commentary). In the current context of the pandemic, they urge us to consider: How can new possibilities for new listenings be activated and sustained during and after the pandemic? Making sense of this moment of rapid change calls for radically re-envisioning language learning environments and for harnessing inclusive language pedagogies.

There has been an explosion of blog posts and blog series since the beginning of the pandemic dedicated to insights, challenges and opportunities to teaching and learning (see, for instance, 'Teaching and Learning during a Pandemic Blog Series' of the Albert Shanker Institute and 'Learning from Lockdown'). Blog posts have sought to challenge the "learning loss" narrative and redirect the conversation to possible futures that are grounded in participatory and dialogic ways of knowing and being (McKinney de Royston \& Vossoughi, 2021). The authors of these blog posts position learners as "knowledge producers and cocontributors to knowledge communities" with the purpose of developing "critical, creative and design thinking" (Kalantzis \& Cope, 2020). They decentre the educator as the sole keeper of authoritative and legitimate knowledge that deposits a predetermined body of knowledge in the minds of learners, what Paolo Freire (1972) has referred to as the "banking model of education". Instead, they advocate for culturally and emotionally responsive learning environments where teachers and students "co-construct curricula and knowledge" (Madkins \& Paterson Williams, 2020). These learning environments foster partnerships and reciprocal relationships between educators, learners, their families and communities and support core values of equity and "being part of a wider nurturing culture" (Shindler, 2020). The chapters and commentaries in this book can contribute to these conversations by pointing to new ways that new listenings can be made possible. They provide theoretical and 
methodological tools to interrogate how the pandemic is reshaping language learning and teaching in the present and long-term.

In the remainder of the section, we outline three indicative projects that investigate the lived experiences of educators, learners, their families, and communities during the pandemic and that can open up new possibilities for listening to what is happening on the ground. These projects remind us that learning happens everywhere and at all times. The first project is a new virtual events series called 'Re-imagining language education during and after Covid-19: Opportunities, challenges and possible futures'. It seeks to bring together a wide range of stakeholders, including language educators from formal and non-formal educational settings, parents, researchers, policy makers and other interested parties to share stories of change and collectively reflect on the impact of the pandemic on language learning and multilingualism in the UK and beyond. The events series is a collaboration of language educators, researchers and policy makers working in the fields of multilingualism and heritage/community/world languages education from UCL BiLingo, the Centre for Language, Culture and Learning, Goldsmiths, University of London and Healthy Linguistic Diet (hld). The inaugural panel discussion focused specifically on the impact of the pandemic on community/heritage language learning, asking the following questions: How have language educators, parents and students experienced the increased role of new technologies and remote learning? How has online teaching facilitated (or not) student and parental engagement and learner-centred instruction? How has community building been supported during the restrictions? What are the gains and what are the losses and for whom? What issues of inclusivity and social justice might they raise? What new visions of community languages education might be emerging during and after the Covid-19 pandemic?

The second project is a small-scale qualitative study on 'Making sense of online teaching and learning in the Covid-19 pandemic'. Vally Lytra probes into language educators and parents' experiences of the digital mediation of teaching and learning in Switzerland. Between July and September 2020, she conducted 20 reflective interviews with language educators and mothers of children attending different forms of Greek community language education. She explores what new possibilities and constraints for sustaining community languages and cultures in the diaspora might be emerging in the present and long-term (Lytra, 2020a; 2020b). The third project 'Language in Multilingual Families during the Covid-19 pandemic' is a larger, longitudinal study using surveys and interviews. It investigates how school closures and social distancing measures during the Covid-19 pandemic may have affected beliefs about multilingualism and language use in multilingual families in the UK and Ireland. It is led by researchers at the Centre for Literacy and Multilingualism and Bilingualism Matters@Reading at the University of Reading in collaboration with researchers from CamBilingNetwork at the University of Cambridge, UCL BiLingo at UCL, the University of Oxford and NALDIC, Mother Tongues Ireland, and We Live Languages (Serratrice et al., 2020). Taken together these projects open spaces for critical dialogue and can provide directions for future research and community engagement in language education post-pandemic.

\section{Implications for curriculum policy, pedagogy and research}

The chapters in this book reflect the complex ecosystem in which language education operates and point to a range of ways in which language education can be revitalised. For purposes of clarity we have summarised them under five broad headings below, but there are many connections and overlaps and this needs to be borne in mind. 
Develop an integrated and inclusive multilingual approach to language education by:

recognising and supporting multilingual repertoires

- encouraging dialogue and collaboration between colleagues working in different areas of language and in different sectors of education (mainstream and complementary) drawing on opportunities created by a multilingual approach to develop literacy and foster critical metalinguistic awareness.

Give greater emphasis to intercultural, experiential and personal perspectives to language education by:

- $\quad$ opening up translingual/transcultural spaces and encouraging translanguaging

- $\quad$ fostering affective, multisensory and aesthetic aspects of language and language learning supporting learning beyond the classroom

- $\quad$ fostering learner agency and voice.

Draw on interdisciplinary approaches by:

- $\quad$ supporting arts-based approaches to language-and-culture learning

- $\quad$ encouraging collaborations between Languages and Art \& Design teachers

- $\quad$ incorporating an activist citizenship strand within language education policy and pedagogy

developing interdisciplinary courses / schemes of work drawing on Content and Language Integrated Learning (CLIL)/thematic/Project Based Language Learning (PBLL) approaches exploiting opportunities for creative and critical use of digital media collaborating with museums, galleries and other organisations.

Adopt an approach to research which recognises different ways of knowing and supports a range of methods reflecting different perspectives by:

- $\quad$ extending range of research methods to take account of shift towards multimodal, spatial, material and sensory conceptual lenses in language and literacy research valuing practical and processual as well as propositional modes of knowledge where appropriate engaging with participants in more democratic, collaborative and personalised ways.

Ensure a critical and decolonising stance towards language education by:

- challenging monolingual discourses

- $\quad$ supporting collaborative power relations in school policy and in the classroom

- $\quad$ implementing principles of democracy and social justice

- developing critical digital literacy.

\section{Liberating language education in relation to local and global issues of diversity, inclusion, citizenship and communication}

How does the research presented here open up new ways of viewing language education? In the final section of this book, we look at how these new perspectives on language education lead into the wider language debates around diversity, inclusion, citizenship and communication. We argue for a change in the way that language education is perceived and 
the need for flexibility, creativity and openness in the ways we approach language and culture.

\section{Diversity}

Diversity matters and the ideas, projects and research brought together in these chapters add to new and diverse ways of representing the multilingual speaker. Liberating Language Education's collective engagement with a diversity of multilingual speakers and new forms of learning, representing and performing languages contributes to the growing debate about decolonising multilingualism and the challenge of 'breaking the politics of representation and presentation' (Phipps, 2019: 91). Our desire to liberate language education and open up access is part of the wider debate around new forms of communication, opening our classrooms to diverse ways of learning, and connecting offline and online networks and communities. We recognise the blurring of boundaries between formal and non-formal education and add our collective voices to the demand for digital technology to be used in more creative and critical ways within language education. Herrero (2020) points out that new media literacies is an underdeveloped area in the language curriculum that calls for new research projects and argues, 'the rise of participatory culture in the $21^{\text {st }}$ century has also shifted the focus of literacy from individual expression to community involvement' (ibid: 189). Our research leads the way in recognising that language education must be personal, aesthetic and political to engage learners and educators across languages and cultures.

\section{Inclusion}

Liberating and opening up spaces for language education is about how we perceive and value languages and cultures and the research in this book contributes to new debates and critical perspectives on inclusion. Project-based language learning is prominent across the chapters in this book and an approach to learning that values agency, collaboration and creativity. These new practices of inclusion struggle against fragmented and inadequate language policies and demand more inclusive, engaging and exciting ways to learn languages. These ideas contribute to the wider debate on multilingualism and education and the importance of showing new ways forward and how actuality implies possibility in new practices of inclusion (Mary et al., 2021). Collaboration is at the root of this book and our approach towards research and innovation. As well as thinking about an inclusive approach to language learning and education it is about an inclusive approach towards researching and sharing knowledge and new ways of thinking about languages. This book contributes to the collaborative construction of new linguistic realities (Moore et al., 2020). The debate here is also about making connections across local and global communities and how we can foster inclusive, intercultural and transformative conversations disrupting divisive and elitist forms of knowledge. Liberating Language Education adds to the debate on ways of knowing and the importance of valuing community literacies (Pahl \& Rowsell, 2020) and connecting different sites of learning.

\section{Citizenship}

An ethic of social justice runs through the ideas, projects and research brought together in this book and contributes to how we perceive and what we mean by liberating language education. As editors of the book, we thought carefully about our own positions as local and global citizens and defined how we encountered and learnt languages as the weaver, the fool, 
the traveller and the activist. In the final pages of this book, we now look at how researching and writing this book, bringing together new and experienced researchers, opening up new opportunities to understand languages and cultures has strengthened our determination to frame language education as a fundamental human right. The ideas presented here contribute to arguments around literacy and power and how an ethic of social justice in our research is vital 'to protect our own rights and the rights of others' (Janks, 2010: 98). In so doing, we have added to the wider debate that citizenship has to be approached as a lived and participatory experience whose ideas and practices are open to change (Peutrell, 2019). Liberating Language Education contributes to this debate on how we want this change to happen and the role languages will play within these wider debates about ways of living locally and globally.

\section{Communication}

At the root of communication is the need to share and make common our ideas and be open to new ways of knowing. In Liberating Language Education we have integrated and embraced multisensory and multimodal approaches to language learning and sought to show how these approaches connect learning across different spaces. Experiencing the pandemic has shown the stark need to enable learners to navigate these different online and offline spaces and find new forms of expression and connection. This debate about language education contributes to the fundamental idea that learning is about communication and that communication is dialogic. Communication is also noisy, disruptive and messy playing and experimenting with contradictions and tensions and slowly allowing meaning to emerge out of dialogue and connection. It is this connection and relationship and 'the play of different voices in dialogue together' (Wegerif, 2013: 3) that makes teaching and learning possible and learners can 'find their own voice in a new and unfamiliar situation' (ibid: 35 ).

Communication opens up possibilities and the discussion here contributes to research looking at how digital technology can offer new 'unbounded contexts' (ibid: 3 ) for language education and the arts can offer 'new ways to engage with people's complex communicative repertoires and represent the open-endedness of changing lives' (Creese, 2020: 253).

Finally, Liberating Language Education, is about taking a critical stand and arguing for ways language education can be transformed. It is about how learners and educators can access and share resources and ideas across different online and offline spaces. It is about why language education matters and why it is important to (re)connect with 'the lost words' (Morris \& Macfarlane, 2018) and new words in multisensory, multimodal ways and better understand our communities, languages and cultures.

\section{References}

Beckett, G. and Slater, T. (eds) (2019) Global Perspectives on Project-Based Language Learning, Teaching, and Assessment: Key Approaches, Technology Tools, and Frameworks. New York: Routledge.

Creese, A. (2020) Afterword. In E. Moore, J. Bradley and J. Simpson (eds)

Translanguaging as Transformation: The Collaborative Construction of New Linguistic Realities, 251-253. Bristol: Multilingual Matters.

Freire, P. (1972) Pedagogy of the Oppressed (M. Bergman Ramos, trans.) London: Penguin (original work published 1968). 
González, N., Moll, L. and Amanti, C. (eds) (2005) Funds of Knowledge: Theorizing

Practices in Households, Communities, and Classrooms. Mahwah, NJ: Lawrence Erlbaum.

Herrero, C. (2019) Conclusion: Present and future directions for video, film and audiovisual media in language teaching. In C. Herrero and I. Vanderschelden (eds) Using Film and Media in the Language Classroom (pp. 188-197). Bristol: Multilingual Matters.

Janks, H. (2010) Literacy and Power. London: Routledge.

Kalantzis, M. and Cope, B. (2020) 'After the COVID-19 crisis: Why higher education may (and perhaps should) never be the same. Scholar, accessed 31 January 2021

https://cgscholar.com/community/community_profiles/new-

learning/community_updates/114650

Lytra, V. (2020a) 'Making sense of online teaching and learning in the Covid-19 pandemic: Emerging themes'. Paper presented at the webinar Community Language Education before and after the COVID-19 Pandemic: Challenges and Innovations - The New Normal for Languages at Home, School and in the Community. Bilingualism Matters, 4 September

Lytra, V. (2020b) 'What can we learn about pedagogy and community building from language teachers and parents' experiences with online teaching and learning in Switzerland?'. Panel discussion on Community/heritage language learning during the Covid19 pandemic: Lessons for pedagogy and community building. UCL BiLingo, the Centre for Language, Culture and Learning, Goldsmiths, University of London and Healthy Linguistic Diet (hld), 10 December

Madkins, T.C., and Patterson Williams A. (2020) 'We choose to reimagine education: Centering on love and emotionally responsive teaching and learning', Shanker Blog, blogpost 14 August, accessed 31 January 2021 https://www.shankerinstitute.org/blog/we-choosereimagine-education-centering-love-and-emotionally-responsive-teaching-and-learning

Mary, L., Krüger, A-B. and Young, A. (eds) (2021) Migration, Multilingualism and Education: Critical Perspectives on Inclusion. Bristol: Multilingual Matters.

McKinney de Royston, M. and Vossoughi, S. (2021) 'Fixating on pandemic "learning losses" undermines the need to transform education', Truthout, blog poste 18 January, accessed 31 January 2021 https://truthout.org/articles/fixating-on-pandemic-learning-lossundermines-the-need-to-transform-education/

Moore, E., Bradley, J. and Simpson, J. (eds) (2020) Translanguaging as Transformation: The Collaborative Construction of New Linguistic Realities. Bristol: Multilingual Matters.

Morris, J. and Macfarlane, R. (2017) The Lost Words. London: Hamish Hamilton.

Pahl, K. and Rowsell, J. (2020) Living Literacies: Literacies for Social Change. London: The MIT Press.

Peutrell, R. (2019) Thinking About Citizenship and ESOL. In M. Cooke \& R. Peutrell (Eds) Brokering Britain, Education Citizens. Bristol: Multilingual Matters.

Phipps, A. (2019) Decolonising Multilingualism. Bristol: Multilingual Matters. 
Serratrice, L., Flynn, N., Joseph, H., Wolleb, A., Wilson, E., Katsos, N., Argyri, F., Murphy, V., Chalmers, H., La Morgia, F., and Xanthopoulou, M. (2020) Language in multilingual families during the Covid-19 pandemic. Report Phase 1 Study- July 2020, accessed 31 January 2021 https://research.reading.ac.uk/celm/our-research/research-projects/language-inmultilingual-families-during-the-covid-19-pandemic/

Shindler. D. (2020) 'In Search of imagining what it means to be a teacher', Learning from Lockdown, blog posted 1 June, accessed 31 January 2021 https://bigeducation.org/lflcontent/in-search-reimagining-what-it-now-means-to-be-a-teacher/

Thayer Snyder, T. (2020) 'Teresa Thayer Snyder: What shall we do about the children after the pandemic?', Diane Ravitch's Blog, blog post 12 December, accessed 31 January 2021 https://dianeravitch.net/2020/12/12/teresa-thayer-snyder-what-shall-we-do-about-thechildren-after-the-pandemic/

Wegerif, R. (2013) Dialogic: Education for the Internet Age. London: Routledge.

Zipin, L., Sellar, S., and Hattam, R. (2012) Countering and exceeding "capital": A "funds of knowledge" approach to re-imagining community. Discourse: Studies in the Cultural Politics of Education, 33 (2), 179-192 